\title{
A EXPERIÊNCIA DO TEMPO NA FORMAÇÃO DO IMPÉRIO DO BRASIL: AUTOCONSCIÊNCIA MODERNA E HISTORICIZAÇÃO
}

\author{
Valdei Lopes de Araúio
}

Prof. adjunto de Teoria da História - Universidade Federal de Ouro Preto

\section{Resumo}

Neste artigo são investigadas as transformações na experiência do tempo no Brasil nas primeiras décadas o século XIX. Procurou-se demonstrar a existência de uma descontinuidade conceitual entre a geração da Independência e a dos homens que construíram o Estado-nacional brasileiro. Especial ênfase é dada ao conceito de história, tomado como índice das transformações conceituais cuja principal direção parece ter sido a historicização.

\section{Palavras-chaves}

Historiografia $\bullet$ independência do Brasil $\bullet$ conceito.

\section{Abstract}

This paper deals with the changes in the experience of time in Brazil during the first decades of $19^{\text {th }}$ century. We try to reveal the existence of a conceptual gap between the generation of Independence and the generation of men who building up the Brazilian national state. Special regard is given to the concept of history taken as signal of conceptual changes that the central trend was historicization.

\section{Keywords}

Historiography $\bullet$ Brazilian independence $\bullet$ concept. 


\section{Introdução'}

O conceito de história é um dos instrumentos centrais na experiência do tempo. Um conceito, muito mais que uma simples palavra, é um agregado de experiências que expressa e ultrapassa o contexto no qual emerge. ${ }^{2}$ Expressa porque é produto das experiências disponíveis, ultrapassa porque prefigura o significado que essas experiências poderão assumir. ${ }^{3}$ Neste artigo, procura-se contribuir para o estudo das transformações na experiência do tempo na primeira metade do século XIX no Brasil, em especial para as transformações nas formas de experimentar a história.

No contexto Europeu a conjuntura que vai de 1750 a 1850 marcou uma profunda descontinuidade conceitual. Estruturas fundamentais do mundo no qual ainda vivemos foram produzidas ao longo desses cem anos. Por volta de 1800, filósofos e pensadores como Hegel definiram esse novo tempo como os tempos modernos. Não deve ser de pequena importância o fato de o Estado nacional brasileiro ter encontrado sua primeira configuração no interior desse recorte temporal marcado por intensas transformações. A história de como as relações entre Europa e América afetaram a formação dos tempos modernos ainda está por ser escrita. O objetivo deste artigo é apenas verificar como os tempos modernos foram moldados no Brasil a partir da experiência central da emancipação política e da formação nacional.

O texto está dividido em duas partes. Na primeira, são destacados os usos do conceito de história e a compreensão do "presente" em José Bonifácio de Andrade e Silva. No segundo momento, mapeia-se o esgotamento das soluções teóricas pensadas por Bonifácio e a nova resposta aberta pela geração "romântica". Trata-se de compreender o papel que a constituição do conceito moderno de história desempenhou na construção da identidade brasileira como identidade nacional. O que se observa é uma progressiva historicização das mais diversas

\footnotetext{
${ }^{1}$ Este artigo é uma tentativa de síntese de algumas questões trabalhadas em minha tese de doutoramento, ver ARAÚJO, Valdei Lopes de. A experiência do tempo: modernidade e historicização no Império do Brasil (1813-1845). Rio de Janeiro: Tese de Doutorado, PUC-Rio, 2003.

${ }^{2}$ Cf. KOSELLECK, Reinhart. História dos conceitos e história social. In: Futuro Passado: contribuição à semântica dos tempos históricos, p. 109.

${ }^{3} \mathrm{Na}$ definição proposta por Koselleck: "[...] uma palavra se torna um conceito se a totalidade das circunstâncias político-sociais e empíricas, nas quais e para as quais essa palavra é usada, se agrega a ela". KOSELLECK, Reinhart. Idem, ibidem.
} 
dimensões da vida humana, fenômeno que teve profundas implicações políticas e culturais na configuração do Estado nacional brasileiro.

\section{Os limites do tempo como restauração}

Como secretário da Academia das Ciências de Lisboa, José Bonifácio procurou compreender a história moderna a partir de diversos esquemas narrativos. Em todos eles transparecia uma crescente consciência da superioridade do presente em relação ao passado, em especial no campo das descobertas científicas. De um modo geral, essas narrativas coincidiam com os relatos produzidos pelos pensadores europeus desde a segunda metade do século XVIII, era o movimento que preparava aquilo que Habermas chamou de autoconsciência dos tempos modernos. ${ }^{4}$ Para um rápido exemplo, ver o relato presente no "Discurso contendo a história da Academia entre 1814/15". Tendo como critério para sua narrativa a ascensão e queda das Letras, Bonifácio narra a história do ocidente desde o seu "nascimento" com os gregos, passando pela decadência rápida das letras no Império Romano até seu "renascimento" a partir do século XVI. O presente pode ser então entendido como a continuidade com um movimento iniciado com o renascimento das letras no século XVI.

A possibilidade de narrar a história da humanidade como uma continuidade desde o período clássico até o tempo presente era algo ainda muito recente, a cultura européia, mesmo ao longo do século XVIII, hesitou entre concepções lineares e cíclicas do tempo histórico. Além disso, Bonifácio ainda compreendia a superioridade dos "modernos" quanto ao conhecimento científico, devendo ainda muito aos "antigos" na dimensão mais ornamental das letras. ${ }^{5}$ Desse relato nos interessa, sobretudo, a consciência de um tempo moderno entendido como progressivo pelo menos desde o século XVI.

Não é difícil imaginar que a história de Portugal, do modo como era narrada até então, não poderia facilmente ser encaixada nesse novo tempo europeu. A percepção da progressiva aceleração do tempo histórico ampliava a consciência

\footnotetext{
${ }^{4}$ Cf. HABERMAS, Jürgen. O discurso filosófico da modernidade, passim. Em especial as seções dedicada a Hegel.

${ }^{5}$ Sobre a dimensão histórico-literária da reflexão de Bonifácio, ver ARAUJO, Valdei Lopes de. José Bonifácio, Shakespeare e os Gregos: a língua do Brasil e a imagem nacional, passim.
} 
de atraso do mundo lusitano. Essa consciência parece ter dado sentido de ação para a geração de intelectuais portugueses contemporâneos de Bonifácio. ${ }^{6}$

A primeira dificuldade para sobrepor a história portuguesa a esse movimento geral é óbvia: como entender que, em um contexto europeu de desenvolvimento da civilização, Portugal enfrentasse um tempo de decadência? Para responder a pergunta, Bonifácio se propõe a traçar um "[...] bosquejo da nossa História Literária desde os primeiros tempos da Monarquia até hoje [...]". ${ }^{7}$ Os primeiros desenvolvimentos desta história - para além dos lampejos sufocados pela invasão "sarracena" - têm lugar com a fundação da monarquia no século XII e atinge seu apogeu no século XVI. Durante a União Ibérica, as Letras e as Artes fogem novamente de Portugal. Somente nos reinados de Dom João V e Dom José I as Letras começariam a ressurgir, culminando com a própria criação da "Academia das Ciências de Lisboa", no reinado de Dona Maria I. Se na história européia foi possível identificar um desenvolvimento linear e progressivo a partir do século XVI, em Portugal essa mesma história é formada por lacunas e retrocessos.

Mesmo que o relato afirme um otimismo moderado, a sensação geral de decadência parece se infiltrar no quadro, exigindo outros encaminhamentos. Em comparação com as demais nações européias, faltava a Portugal um grande historiador e uma história filosófica. Para isso era preciso copiar os estrangeiros e iniciar a publicação das antigas cartas e diplomas, "que são a fonte da História". Com a publicação desse material, "[...] poderemos ter um dia quem com Crítica apurada, arte, e bom gosto nos dê um corpo de História pragmática e filosófica; que, é preciso confessar, ainda nos falta. Cumpre esperar que virá tempo, em que tenhamos os nossos Gibbons, e os nossos Humes".

\footnotetext{
${ }^{6}$ Para uma ampla visão do contexto intelectual e político do qual Bonifácio é devedor, ver SILVA, Ana Rosa Cloclet. Inventando a Nação: intelectuais ilustrados e estadistas luso-brasileiros na crise do Antigo Regime Português, passim. Em especial a parte III, integralmente dedicada à análise da atuação de José Bonifácio.

${ }^{7}$ SILVA, José Bonifácio de Andrada e. Discurso, contendo a história da Academia Real das Ciências, desde 25 de junho de 1814 até 24 de junho de 1815 . In: Obras científicas, políticas e sociais, p. 359.

${ }^{8}$ SILVA, José Bonifácio de Andrada e. Discurso, contendo a história da Academia Real das Ciências, desde 25 de junho de 1814 até 24 de junho de 1815 . In: Obras cientificas, politicas e sociais, pp. 367-8, grifos meus. Esse mesmo sentimento de atraso com relação às outras nações européias era comum na Inglaterra da segunda metade do século XVIII. A História da Inglaterra de David Hume (1711-1776) é deliberadamente uma tentativa de suprir essa falta. Em carta comentando seu projeto, afirmaria: "You know that there is no post of honour in the English Parnassus more vacant than that of History". Apud PHILLIPS, Mark S. Society and Sentiment, p. 38.
} 
Essa revisão do passado permitiria uma verdadeira história pragmática e filosófica que talvez pudesse explicar o enigma português, dizer qual a direção do progresso que se esconde por detrás dos sucessivos recuos de sua história. Por que Portugal, que primeiro construiu uma nação moderna, que logo desenvolveu uma língua nacional e um forte Império, perdeu a sua posição? Ao mesmo tempo em que apontaria as causas, essa História poderia ser parte da solução, edificando e preparando os "retratos" sine ira et studio das figuras históricas a serem julgadas, condenadas ou estabelecidas e, neste último caso, imitadas.

No discurso acadêmico de 1818 é possível perceber um crescente incômodo com a divergência cronológica entre as histórias portuguesa e européia. Esperava-se que o estudo do passado pudesse explicar e propor soluções para o descompasso do Império se comparado ao resto do continente: "com efeito, Senhores, sem o socorro de novos documentos e manuscritos, nunca teremos uma história completa e verdadeira, e sem esta nunca poderemos apreciar os progressos que tem feito Portugal nas Letras e na civilização".

Era preciso identificar na história de Portugal as leis do desenvolvimento das civilizações e dos povos. O conhecimento dessas leis serviria não apenas para reforçar a crença no presente - em seu desenvolvimento contínuo com relação ao passado - , mas também para a legitimação de um novo tipo de conhecimento, não a consciência do exemplo moral a ser imitado, mas a descoberta das forças que conduziram a tal resultado e dos mecanismos que atuaram e atuam como motor do processo. Aqui a imagem do passado já está em movimento; interessam menos os quadros individuais, os fragmentos, as épocas isoladas, e mais o desenrolar. $\mathrm{O}$ verbo apreciar utilizado nesse contexto aponta, ao mesmo tempo, para o passado e o futuro, pois certamente era importante visualizar o progresso de Portugal, mas igualmente avaliá-lo e mensurá-lo, de modo a subsidiar os projetos reformistas.

A continuidade com o passado, sua imediaticidade, já não está garantida. Por mais que se tentasse fazer do reinado de Dona Maria I o resultado óbvio desse processo de restauração, outro evento infiltrava-se e simultaneamente minava o quadro estabelecido, exigindo novos e maiores esforços para garantir o que antes parecia estar à mão, i.e., a continuidade com o passado. Esse evento era a Revolução Francesa, pois, para Bonifácio, tratava-se de saber “"[...] como

${ }^{9}$ SILVA, José Bonifácio de Andrada e. História da Academia Real das Ciências de Lisboa. Discurso lido em 1818. In: Obras cientificas, politicas e sociais, p. 421. Grifos meus. 
também por meio de guerras e tratados, e por novas providências e estabelecimentos, chegamos a gozar de sossego, segurança e força que tínhamos antes da revolução Francesa [...]". ${ }^{10}$

A Revolução Francesa insere um dado radicalmente novo que parece explodir com as tentativas de recuar o presente em um processo direto desde a restauração de 1640. Portugal parecia caminhar firme em uma ascensão progressiva até 1789, a Revolução marcaria o retorno da desordem e da intranqüilidade, a interrupção de um processo que havia sido retomado por Dom João IV.

As palavras iniciais do último discurso de Bonifácio na Academia das Ciências, às vésperas de retornar ao Brasil, indicam uma reorientação: “[...] pois é forçoso abandonar o antigo, que me adotou por filho, para ir habitar o novo Portugal, onde nasci". ${ }^{11}$ A oposição entre o velho e o novo, entre o exausto e o exuberante, entre o contaminado e o puro, organiza todo o texto. O tom progressivamente crítico e pessimista - que ano a ano corroia o projeto de restauração, cada vez mais evidente na reflexividade dos textos - cede lugar a um otimismo renovado. A restauração de Portugal é deslocada pelo tema da "nova Lusitânia". ${ }^{12}$ Seu retorno ao Brasil é descrito como o início de uma tarefa civilizadora, não mais uma restauração, mas um recomeço.

No mesmo discurso Bonifácio apresenta uma longa lista das vantagens e dos potenciais do Brasil: a grandiosidade dos recursos naturais e uma posição geográfica vantajosa, entre a Europa, a América e a África. Pelo lado político, o Brasil não teria os vícios arraigados de Portugal; seu clero seria abastado, mas sem riqueza inútil, com poucos poderosos que pudessem sobrepor seus interesses individuais aos da Nação. Diante desse quadro, era possível acreditar que, para a civilização do Brasil, bastariam “"[...] a segurança pessoal e a liberdade sóbria de imprensa, de que já goza; e uma nova educação física e moral: o mais pertence à natureza e ao tempo". ${ }^{13}$

Em um contexto em que a existência do Reino do Brasil, da forma como foi estabelecida por Dom João VI, era intensamente questionada, em que o retorno do monarca era reivindicado e culminaria em uma revolução, as palavras finais de Bonifácio marcavam uma firme decisão de reorientar sua ação como letrado.

\footnotetext{
${ }^{10}$ Ibidem, p. 422. Grifos meus.

${ }^{11}$ SILVA, José Bonifácio de Andrada e. Discurso histórico recitado na sessão pública de 24 de junho de 1819 pelo secretário JBAS. In:

${ }^{12}$ Ibidem, p. 472.

${ }^{13}$ Ibidem, p. 473. Grifo meu. Obras cientificas, políticas e sociais, p. 445. Grifo meu.
} 
O Novo Portugal não surgirá da restauração do velho Portugal, mas de sua regeneração no Novo Mundo: “[...] pois a fundação da Monarquia Brasílica fará uma época na História futura do Universo". ${ }^{14}$

Além de um deslocamento geográfico, a substituição do projeto da restauração pela regeneração respondia à sensação tanto de uma possível irreversibilidade da "retrogradação" de Portugal, quanto da aceleração do tempo tantas vezes observada por Bonifácio. Esse movimento não significava um abandono de Portugal. Parecia indicar que não haveria como o velho reino produzir por si mesmo sua restauração.

Embora carregue ainda uma solução de compromisso entre o novo e o antigo, o conceito de regeneração parecia mais permeável ao movimento, assim como abre maior espaço para a inovação. ${ }^{15}$ Simultaneamente, para produzir tais efeitos e ampliar as expectativas, o conceito desloca o tempo, amplia sua faixa de referência que deixa de ser apenas a história da restauração portuguesa após a União Ibérica - ou mesmo a imagem de um Portugal rural dos tempos da fundação da monarquia - para se integrar de vez a uma História Universal, com um futuro maior e diferente do passado.

Considerado apenas por sua história como reino, Portugal parecia já ter atingido o ponto máximo de sua civilização. Iniciar uma nova carreira significava realizar uma ampliação de perspectivas e uma mudança de cenários capazes de incorporar o novo e a ruptura na experiência do tempo.

\section{A regeneração de Portugal}

De volta ao "Novo Portugal", Bonifácio escreve sobre a necessidade de uma Academia de Agricultura. Nesse texto, é visível a relação entre o projeto de regeneração e um conceito clássico de colonização, pois, nas palavras de Bonifácio, “[...] a nação portuguesa, aqui reproduzida, como em outro tempo os Troianos na formosa Itália, recobrando a sua antiga energia, há de outra vez dar lições ao mundo [...]" ${ }^{16}$ O Brasil deveria ser entendido como colônia, mas

\footnotetext{
${ }^{14}$ SILVA, José Bonifácio de Andrada e. Discurso histórico recitado na sessão pública de 24 de junho de 1819 pelo secretário JBAS. In: Obras cientificas, políticas e sociais, p. 473.

${ }^{15}$ Para uma visão geral sobre a importância dos conceitos de movimento na modernidade, ver KOSELLECK, Reinhart. Modernidade - sobre a semântica dos conceitos de movimento na modernidade. In: Futuro passado, p. 267-303.

${ }^{16}$ SILVA, José Bonifácio de Andrada e. Necessidade de uma academia de agricultura no Brasil. In:__. Obra política, p. 35-6. Grifos meus. O topos clássico parece reforçado pelo tom cíclico
} 
não no sentido moderno, e sim tendo como modelo a experiência antiga, em que a ação colonizadora não significava a dependência política e econômica da metrópole, mas a expansão dos princípios fundamentais da cidade-estado original. A velocidade dos acontecimentos logo desafiaria os limites dessa interpretação. Nesse período pode-se verificar o uso cada vez menos central do léxico "restauração". Em um primeiro momento regeneração parece comportar o campo semântico do antigo vocábulo, mas logo vai se afastando dele em direção a significados mais dinâmicos e orgânicos, realizando uma lenta passagem das metáforas mecânicas para imagens mais organicistas.

Em 1820, Bonifácio tornou-se conselheiro do Dom João VI; em 1821, como desdobramento do movimento constitucionalista do Porto, foi nomeado vicepresidente da Junta Provisória da província de São Paulo. Desse mesmo ano data suas "Lembranças e Apontamentos" aos deputados paulistas eleitos para as Cortes de Lisboa. O documento é um registro preciso da nova cronologia que ensaiara em seu discurso de despedida da Academia das Ciências, embora aqui precise responder a outras formas de superação do projeto restaurador, em especial a regeneração política empreendida pelos liberais de Portugal. Bonifácio compreendia a regeneração proposta pelas Cortes como a refundação do pacto social em bases compatíveis com o espírito do século. A regeneração política só poderia reverter a decadência do velho reino se compreendesse a prioridade de uma regeneração maior e mais fundamental que deveria ter como cenário o Brasil.

Tratando-se de um novo pacto político, a unidade dos reinos de Portugal e do Brasil, que formariam juntos o Império, deveria ser garantida em novas bases, de modo

[a] completar o Augusto projeto da nossa Regeneração Política e recíproca união; objeto capital, que requer de todo o bom patriota imparcialidade e boa fé, madureza e crítica apurada, para que os laços indissolúveis, que hão de prender as diferentes partes da monarquia em ambos os Hemisférios, sejam eternos como esperamos $[\ldots]{ }^{17}$

da passagem.

${ }^{17}$ SILVA, José Bonifácio de Andrada e. Lembranças e Apontamentos... In: p. 95. Grifo meu. Obra política, 
A preocupação central do texto é com a integridade do Império, título, aliás, da primeira seção. A desilusão com as possibilidades do Reino de Portugal e o exemplo da fragmentação política das ex-colônias espanholas acirravam a preocupação com o futuro do Brasil. A única esperança de regeneração de Portugal era a potência territorial, natural e moral dessa parte do Império, daí a centralidade de sua manutenção integral. Por isso, o texto volta-se para as iniciativas que deveriam garantir a prosperidade do Reino do Brasil: a civilização dos selvagens, a emancipação dos escravos, as reformas estruturais, a criação de faculdades, entre outras.

A organização do Reino do Brasil parecia exceder o passado vivido e os homens reais. Em seu lugar é proposta uma imagem típica de um passado-modelo e a fabricação de homens renovados a partir de uma população amorfa. $\mathrm{O}$ abandono de Portugal significava a possibilidade de se desvencilhar dos entraves e desgastes de seu passado. Em uma compreensão, em grande medida, cíclica e "fechada" do desenvolvimento das civilizações, o Brasil poderia representar um novo começo. Na descrição da cidade central que deveria ser a nova capital, o discurso esquecia sua direção política e deixava escapar o desejo de que, pelas reformas, “[...] se favoreça [...] o comércio interno do vasto Império do Brasil". ${ }^{18}$ Onde estaria o espaço para esse Império do Brasil, se, na abertura do texto, eram definidas as bases da arquitetura do novo pacto político sob a idéia de um Império Lusitano formado por dois reinos? Não estaria no presente da regeneração política proposta pelas Cortes, mas na profundidade desse novo tempo anunciado pelo "Patriarca". ${ }^{19}$

O projeto de regeneração proposto por Bonifácio parecia ultrapassar a simples refundação política pensada pelos liberais de Portugal. A nova cronologia, que já se infiltrava em seus discursos como secretário da Academia das Ciências, minando o projeto da restauração, torna-se projeto e utopia no Brasil. As implicações dessa nova experiência do tempo orientarão sua compreensão do processo de Independência. Essa ampliação da capacidade dos sujeitos produzirem sua própria história é um dos clássicos sintomas da abertura do cronotopo moderno. ${ }^{20}$

\footnotetext{
${ }^{18}$ Ibidem, p. 99.

${ }^{19}$ A dimensão utópica dessa experiência histórica foi longamente analisada por LYRA, Maria de Lourdes Viana. A utopia do poderoso império, passim.

${ }^{20}$ Para a definição da categoria "cronotopo", ver GUMBRECHT, Hans Ulrich. Cascatas de modernização In: . Modernização dos sentidos, p. 9-32; e ainda, ARAUJO, Valdei Lopes de. Para
} 
Reagindo à crise da relação com as Cortes, Bonifácio redigiu uma série de representações e ofícios, através dos quais é possível mapear, com algum detalhamento, o desenvolvimento de suas posições. Os liberais de Portugal são acusados de empreender uma tentativa de "retrogradação colonizadora" destinada a retirar do Brasil seus direitos adquiridos. Quando percebe que a conjuntura parecia levar à emancipação política do Brasil, Bonifácio apropria-se do discurso de alguns setores da elite política que procuraram identificar as Cortes com um projeto "recolonizador" e com o absolutismo. ${ }^{21} \mathrm{O}$ tema da colônia antiga cedia à realidade de uma colonização moderna, fundada na exploração.

Como ameaça à unidade do Império, as Cortes assumiam o peso morto do passado português. Podiam agora ser identificadas com o velho, o estacionário e o retrógrado, deixando ao Brasil a imagem de um outro Portugal, clássico e antigo - por ser norma e referência -, mas não velho, inútil ou retrógrado. Assim, para enfrentar a contração geral das expectativas adiante da regeneração política, que de súbito deixava de representar as idéias liberais do século, iniciava-se um processo fundamental de releitura da história dos portugueses no Brasil, transformando-a em história do despotismo. Essa reinterpretação já era possível nos últimos discursos da Academia, mas é a ruptura com as Cortes que tornou necessária a sua exibição integral. Entretanto, em nenhum momento, a perspectiva de unidade do Império Português é abandonada. Ao contrário, sua necessidade e prioridade é que legitimavam as reivindicações dos portugueses do Brasil, afirmados como portadores da mesma natureza e direitos dos europeus, pois a nação portuguesa "[...] é sempre a mesma; [...] os mesmos sentimentos a animam, quer habite um, ou outro hemisfério". ${ }^{22}$

Mesmo que não encontrasse mais sua imagem em um passado imediato, vivido, o tempo renovado que a regeneração de Portugal no Brasil oferecia ainda era orientado por princípios imutáveis, as quais, como germes adormecidos, esperavam apenas novas energias para desenvolverem a imagem fixa gravada em seu interior. A História do Brasil passa, então, a espelhar a de Portugal, mas agora isso significava a ruptura com seu velho centro, e seu projeto "moderno":

além da autoconsciência moderna: a historiografia de Hans Ulrich Gumbrecht, p. 314-328.

${ }^{21}$ Sobre a centralidade do topos da recolonização para a conjuntura, ver BERBEL, Marcia Regina. A nação como artefato: deputados do Brasil nas cortes portuguesas (1821-1822).

${ }^{22}$ SILVA, José Bonifácio de Andrada e. Representação de 31 de dezembro de 1821. In: Obras científicas, políticas e sociais, p. 229. 
A História do Brasil atesta esta verdade. As heróicas proezas dos Pernambucanos, por espaço de sete anos, contra seus tiranos invasores, os holandeses; os gloriosos, e felizes esforços dos Baianos, Fluminenses, e outros povos, repelindo, por vezes, agressões estrangeiras, são exemplos, que assaz evidenciam quanto os portugueses nascidos no Brasil, prezaram sempre a independência, ainda, quando agrilhoados pelo bárbaro despotismo. ${ }^{23}$

O tema central do despotismo surge com força, embora não seja possível definir, com certeza, se a referência está endereçada apenas às potências estrangeiras que, em vários momentos, ocuparam o território brasileiro, ou se também está dirigida à ação dos portugueses. A introdução da questão pelo advérbio ainda permeia o texto de uma ambigüidade irônica. O discurso parece tirar uma especial produtividade dessa ambigüidade; a todo o momento a diferença é introduzida e moderada por elementos de continuidade. Os portugueses dos dois lados do Atlântico agora são marcados por seu nascimento. À identidade tautológica da nação lusitana são sobrepostos novos elementos de identificação que se acumulam, vertical e horizontalmente, nos textos do período: brasileiros, brasílicos, paulistas, portugueses do Brasil, nascidos no Brasil, súditos, cidadãos, habitantes, povo, natural, etc. Os adjetivos proliferavam em um momento no qual se redefiniam, a cada instante, as fidelidades e pertencimentos que por séculos pareceram tão sólidos.

Ao longo do processo de emancipação, Bonifácio não abrirá mão do horizonte de totalidade oferecido pela imagem do Império, ainda que a reunião fosse adiada para um futuro cada vez mais incerto. Paralelamente, era preciso estabelecer as bases nas quais a Independência do Brasil poderia ser concebida: em ruptura com as Cortes, mas em harmonia com o projeto de regeneração que vislumbrara ainda em Portugal. Numa operação complexa, a negação do agora passado-despotismo era feita em nome de virtudes e princípios lusitanos dos quais os brasileiros seriam herdeiros.

Essa herança não vem de um passado empiricamente datado, representa apenas um conjunto de valores típicos. Já o passado recente (e dentro em pouco todo o passado português no Brasil) será interpretado como uma longa história de opressão. Ao mesmo tempo, abria-se a possibilidade de outro relato, de outra história que já não poderia mais ser de Portugal. Em um primeiro momento a crítica parece circunscrita aos últimos acontecimentos; a ação dos liberais de

\footnotetext{
${ }^{23}$ Ibidem, idem. Grifos meus.
} 
Portugal seria produto da cegueira e o egoísmo de alguns, e os direitos reivindicados pareciam não ter outro fundamento que a generosidade de Dom João VI em 1808.

Ao longo do ano, entretanto, à medida que os acontecimentos encaminhavam para uma inevitável ruptura política, a sombra do absolutismo vai se ampliando até tomar conta de todo o passado português no Brasil. Aos poucos a imagem de um Portugal decadente e velho vai se sobrepondo, e a crítica pode agora abarcar e explicar as ações dos homens envolvidos na condução da regeneração política. Os portugueses da Europa, talvez por sua decadência e vício, não entendiam que a única possibilidade de regeneração de Portugal era o Brasil. Neste conflito de interpretações, projeta-se uma diferença fundamental de cronologia. Se o projeto português em realização estava voltado para a solução da crise cultural, econômica e social em que vivia o Reino, o projeto de Bonifácio, como visto, estava orientado para um futuro que, embora já tivesse começado, era muito mais distante e correspondia a um aprofundamento do passado em narrativas progressivas. Do ponto de vista do Império do Brasil os liberais portugueses eram apenas "[...] um pequeno número de desorganizadores". ${ }^{24}$

Datado de seis de agosto de 1822, o Manifesto do Príncipe Regente é um dos documentos mais importantes e reveladores do período. Do ponto de vista das preocupações deste relato, é fundamental notar a unificação do passado brasileiro pré-1808, ou seja, anterior à elevação do Brasil à categoria de Reino, sob a rubrica de colônia ou colonial. Esta operação cronológica legitima e orienta o processo de emancipação. É graças a ela que o Brasil pode assumir uma voz como sujeito de uma história que não é mais portuguesa. ${ }^{25}$ Isso fica evidente quando "Dom Pedro" afirma que resolveu:

[...] Anuir a vontade geral do Brasil que proclama a face do Universo a sua Independência política; e quer, como Reino irmão, e como nação grande e poderosa, conservar ilesos e firmes seus imprescritíveis direitos, contra os quais Portugal sempre atentou $\left[\ldots . .{ }^{26}\right.$

\footnotetext{
${ }^{24}$ SILVA, José Bonifácio de Andrada e. Suplemento ao número 4 da Gazeta do Rio, de 8 de janeiro de 1822. In: Obras cientificas, politicas e sociais, p. 224.

${ }^{25}$ Para uma análise detalhada desse movimento no ápice do processo de Independência, ver PIMENTA, João Paulo. Portugueses, americanos, brasileiros: identidades políticas na crise do Antigo Regime luso-americano. Almanack Braziliense, p. 69-80.

${ }^{26}$ Repare-se, por exemplo, que a vinda da Corte não é mais referida como um favor recebido com júbilo pelos súditos deste lado do Atlântico, mas como uma gentileza dos súditos com uma corte
} 
O processo de separação continua mitigado pela imagem da unidade, que vai perdendo qualquer conteúdo efetivo ou é adiada para um futuro sem data. Os portugueses, que ainda há pouco eram os mesmos nos dois lados do Atlântico, agora são irmãos em um sentido bastante abstrato. $\mathrm{O}$ absolutismo lusitano, primeiro circunscrito a um pequeno grupo de egoístas e falsos liberais, agora é atribuído a todo Portugal, e desde sempre:

Quando por um acaso se apresentara pela vez primeira esta vasta e rica região brasílica aos olhos do venturoso Cabral, logo a avareza e o proselitismo religioso, móveis dos descobrimentos e colônias modernas se apoderaram dela por meio de conquista, e leis de sangue, ditadas por paixões e sórdidos interesses, firmaram a tirania portuguesa. $\mathrm{O}$ índio bravio e o colono europeu foram obrigados a trilhar a mesma estrada de miséria e escravidão. ${ }^{27}$

No mesmo trecho, são alinhados os dois conceitos de colônia: o moderno, produto da conquista e do egoísmo, e o antigo, representado pelo colono oprimido. A ênfase nas diferenças entre os dois modelos é reveladora de uma reorientação crítica na avaliação dos tempos modernos. Se a História de Portugal já não se ajeitava bem ao relato de um desenvolvimento linear e progressivo desde o Renascimento, agora é a própria história européia que é reavaliada em suas relações com a América, afinal, conclui Bonifácio: "Sempre quiseram os europeus conservar este rico país na mais dura e triste dependência da metrópole [...]". ${ }^{28}$

A história da colonização como história da exploração permite a tão desejada unidade do Brasil para além de um projeto de restauração de Portugal. Só a partir desses princípios abstratos é que se poderia, em uma expressão, reunir o que ainda era fragmento e caos. Agora o Brasil tinha um destino diferente do português, um princípio perante o qual o presente poderia reagir. De que outro modo entender o vigor da experiência histórica que se resume na frase: "Tal

enfraquecida: "Porém, o Brasil, ainda que ulcerado com a lembrança de seus passados infortúnios, sendo naturalmente bom e honrado, não deixou de receber com inexplicável júbilo a augusta pessoa do Senhor D. João VI, e toda a Real Família”. SILVA, José Bonifácio de Andrada e. Manifesto do Príncipe Regente do Brasil aos Governos e Nações Amigas, datado de 6 de agosto de 1822. In:__. Obras científicas, políticas e sociais, p. 268.

${ }^{27} \mathrm{Ibidem}$, idem. Grifos meus.

${ }^{28}$ SILVA, José Bonifácio de Andrada e. Manifesto do Príncipe Regente do Brasil aos Governos e Nações Amigas, datado de 6 de agosto de 1822. In: . Obras cientificas, politicas e sociais, p. 267. 
foi a sorte do Brasil por quase três séculos [...]?". ${ }^{29}$ A essa, até então, simples parte de Portugal, era conferida um princípio organizador multissecular: o jugo do despotismo.

Com sua própria história delineada, era possível a Bonifácio reivindicar o justo lugar para o Império do Brasil. Diante desse lugar, que se junta a um tempo alargado que contrai o presente, aprofunda o passado e distancia o futuro, o reino de Portugal deveria encontrar seu novo tamanho. Apontando o absurdo da decisão das Cortes em fixar a sede da Monarquia na Europa, Bonifácio observava com indignação a pretensão descabida dessa "mínima parte do território português" e "sua povoação estacionária e acanhada" de ser o "centro político e comercial da nação inteira". ${ }^{30}$

Sem abdicar de um projeto de unidade, ${ }^{31}$ e mesmo em nome desse projeto, ainda que agora inserido no interior de uma nova história, de uma nova era, Bonifácio sepultava as esperanças de uma restauração portuguesa, embora mantivesse, ao lado das promessas de unidade futura e duradoura, a imagem de uma Antigüidade que não mais se confundia com o passado velho ${ }^{32}$ :

Quem ignora igualmente que é quase impossível dar nova força e energia a povos envelhecidos e defecados? Quem ignora hoje, que os belos dias de Portugal estão passados, e que só do Brasil pode esta pequena porção da monarquia esperar seguro arrimo, e novas forças para adquirir outra vez a sua virilidade antiga! Mas de certo não poderá o Brasil prestarlhe este socorro, se alcançarem estes insensatos decepar-lhes as forças, desuni-lo, arruiná-lo. ${ }^{33}$

\footnotetext{
${ }^{29}$ Ibidem, idem.

${ }^{30}$ Ibidem, p. 277.

${ }^{31}$ Parte importante da estratégia de reconhecimento da Independência do Brasil assentava-se no argumento desenvolvido ao longo do Manifesto de que, estando o rei D. João VI cativo das Cortes, o príncipe herdeiro no Brasil era a única autoridade legítima. Logo, uma possível unidade deveria ter o Brasil como cabeça do Império.

${ }^{32} \mathrm{Ou}$, como afirma, "o caruncho do velho despotismo". SILVA, José Bonifácio de Andrada e. Discurso lido em 26 de Janeiro de 1822. In: . Obras cientificas, políticas e sociais, p. 238.

${ }^{33}$ SILVA, José Bonifácio de Andrada e. Manifesto do Príncipe Regente do Brasil aos Governos e Nações Amigas, datado de 6 de agosto de 1822. In: . Obras cientificas, políticas e sociais, p. 278.
} 


\section{0 sistema em ruínas}

No vocabulário político que Bonifácio compartilhou com os homens de sua geração, a palavra sistema ocupou um lugar de destaque. Pensar a realidade como um conjunto de sistemas permitia organizá-la de modo a submetê-la à ação dos homens. O limite desse conceito central estava justamente em sua pouca flexibilidade à mudança, pois o movimento sempre atingia de forma negativa os sistemas. $\mathrm{O}$ conceito de sistema migrou muito rapidamente da reflexão filosófica para o debate político, trazendo consigo um vasto e integrado conjunto semântico. A reflexão filosófica de Silvestre Pinheiro Ferreira talvez possa tornar mais claro o que esses homens faziam quando usavam conceitos como regeneração.

Em suas "Preleções Filosóficas", publicadas entre 1813 e 1815, Pinheiro Ferreira apresentou uma das mais vigorosas sínteses do universo conceitual disponível em língua portuguesa nas primeiras décadas do século XIX. ${ }^{34}$ Para este autor o Universo estava submetido aos movimentos primordiais de atração e repulsão, os princípios responsáveis por todos os fenômenos que se desenvolvem a partir do momento original da criação. Esses fenômenos, por sua vez, poderiam ser classificados em cinco categorias: conservação, perfeição, decadência, transformação e regeneração. ${ }^{35}$ Todos os sistemas, sejam eles físicos ou morais, teriam seus movimentos condicionados por um desses estados fundamentais.

Estando os sistemas em equilíbrio, ou seja, todas as suas partes bem combinadas e ordenadas, o conjunto está em harmonia e conserva-se como totalidade. A conservação é o objetivo primeiro de qualquer sistema. No esforço de sua conservação, os sistemas produzem mais e mais atividade e esse movimento tende a incorporar novas partes ao todo. Quando esse movimento de incorporação não compromete a harmonia do sistema, Ferreira chama o fenômeno de crescimento de energia e aumento de atividade. Os atributos que colaboram para a manutenção harmônica do sistema são suas virtudes. Ao alcançar seu ponto máximo de atividade e energia, o sistema atinge sua perfeição. Mas

\footnotetext{
${ }^{34} \mathrm{Na}$ introdução da segunda edição das "Preleções", Antônio Paim afirma que elas representam a dilaceração da consciência lusitana, dividida entre um mundo físico newtoniano e a permanência dos valores ético-morais do antigo regime. Apud FERREIRA, Silvestre Pinheiro. Preleções filosóficas, p. 12.

${ }^{35}$ FERREIRA, Silvestre Pinheiro. Preleções filosóficas, p. 62.
} 
pode acontecer ainda que o número de partes de um sistema, bem como seu grau de atividade, diminua, mesmo que circunstancialmente algumas partes apresentem maior vigor. Quando isso ocorre, o sistema perde sua identidade, vicia-se e decai. ${ }^{36}$

A transformação ocorre quando há mudanças na relação entre as partes de um sistema, o que pode acontecer por duas formas. Na primeira, quando cessa toda e qualquer ação das partes entre si, resultando em resolução - quando as partes se separam em vários outros sistemas isolados — ou dissolução - se nem mesmo esses sistemas parciais passam a existir, mas apenas partes isoladas. ${ }^{37}$ A segunda forma de transformação ocorre quando ao acrescentarem-se ou perderem-se novas partes altera-se a relação do todo sem mudar, entretanto, a identidade do sistema. A esse fenômeno, Ferreira dá o nome de transmutação ou metamorfose.

Quando a transformação resulta apenas na incorporação de novos elementos e no aumento da atividade, sem mudança na identidade do sistema, ocorre uma comutação, ou seja, o novo material foi revertido na mesma estrutura original, o sistema o transformou em sua própria substância. O mesmo movimento pode resultar na substituição de uma parte danificada ou perdida do sistema. Neste caso, "[...] diz-se que se refez, se reparou com aquela comutação [...]". ${ }^{38}$

O quinto e último fenômeno é o da regeneração, oferecido pela natureza em duas formas distintas. A primeira ocorre quando após ser destruído e ter suas partes desmembradas os princípios de atração e repulsão agem de forma tal a reunir novamente, depois de algum tempo, as partes isoladas e regenerar o sistema a sua forma primitiva, tanto em qualidade quanto em número de partes. O segundo tipo de regeneração, o mais freqüente, tem lugar quando, após ter perdido um de seus membros, o todo restante reconstrói a estrutura ausente utilizando novos materiais incorporados. A esse tipo de regeneração Ferreira denomina renovação. ${ }^{39}$

Junto com a distinção entre forma (acidente) e substância, essa compreensão de um universo organizado e co-relacionado em suas partes hierarquicamente dispostas permite acreditar que uma teoria dos sistemas organizados e a descrição de suas relações causais fossem a tarefa fundamental do conhecimento, tanto

\footnotetext{
${ }^{36}$ Ibidem, p. 62-3.

${ }^{37}$ Ibidem, p. 63.

${ }^{38}$ Ibidem, idem.

${ }^{39}$ Ibidem, p. 65.
} 
das ciências históricas quanto físicas. As grandes convulsões e incertezas que varriam a Europa desde a segunda metade do século poderiam ser compreendidas no interior dessa cadeia hierárquico-causal, pois, escreve Ferreira, “[...] como em todos os fenômenos da natureza, é só pela acumulação de pequenos e insensíveis fenômenos homogêneos, que se formam com o tempo essas comoções, que parecem um transtorno geral do Universo". ${ }^{40}$

Nessa autocompreensão, a tarefa do tempo presente passa a ser a descrição e a organização exaustiva dos fatos físicos e morais:

[...] uma inteligência de ordem superior à humana inteligência, abraçando com a vista o estado presente de todo o Universo, nele, e em cada uma das suas partes, veria representados, como o efeito o é na sua causa, todos os futuros acontecimentos até a mais remota duração dos séculos. ${ }^{41}$

Nesse universo limitado e transparente, era fácil imaginar o presente apenas como o produto de todos os estados anteriores. Tanto o passado quanto o futuro estariam contraídos nesse instante, seja como desenvolvimento-efeito, seja como causa-potência. Não há distância temporal, apenas uma grande unidade ontológica visível a partir de uma perspectiva superior:

A contemplação do Universo, e particularmente a dos grandes fenômenos que nele observamos, facilmente nos conduzem ao conhecimento de uma verdade cosmológica, que é preciso tenhais diante dos olhos [...].

$\mathrm{O}$ presente, dizia o grande Leibniz, está prenhe do futuro. ${ }^{42}$

Mais de uma década depois de Ferreira transplantar a frase de Leibniz, Bonifácio ainda podia recorrer à mesma fórmula. Em 1827, ainda no exílio, comentando com o amigo Menezes a morte da Imperatriz, escreveria: "Es-

\footnotetext{
${ }^{40}$ Ibidem, p. 60.

${ }^{41}$ Ibidem, p. 61. Tratava-se de assegurar o mundo como quadro e o homem como sujeito empenhado em sua representação, "We get the picture concerning something does not mean only that what is, is set before us, is represented to us, in general, but what is stands before us - in all that belongs to it and all that stands together in it - as a system". HEIDEGGER, Martin. The age of the world picture, In: The Question Concerning Technology and Others Essays. Nova York: Harper Torchbooks, 1977, p. 129.

${ }^{42}$ FERREIRA, Silvestre Pinheiro. Preleções filosóficas, p. 58.
} 
peremos; que o presente está prenhe de futuro". ${ }^{43}$ Entretanto, se em Ferreira a crença numa unidade cósmica robustecia um presente otimista quanto suas próprias possibilidades e tarefas, no final da trajetória de Bonifácio a repetição da fórmula agregava outros efeitos. A anteposição marcante do verbo esperar desestabiliza a compreensão mais comum da frase. No último Bonifácio, esses mesmos acontecimentos pareciam agora extrapolar os limites dos conceitos. Do projeto da restauração aos vários entendimentos da regeneração, a crença de que Portugal e Brasil eram partes de um mesmo sistema lusitano em decadência, transformação e regeneração parecia cada vez menos convincente, visto o agressivo afastamento entre os dois mundos. O processo de independência, à medida que reforçava a separação dos dois reinos, não poderia mais ser descrito em termos de restauração ou regeneração. A manutenção da identidade do sistema, mesmo na hipótese-limite do abandono do reino de Portugal e sua renovação no Brasil, cedia à compreensão de que, na América, algo diferente estava em curso. $\mathrm{O}$ enfrentamento dessa descontinuidade não seria tarefa para Bonifácio, que morreria em 1838 sem nunca retomar o protagonismo político dos anos da Independência.

O passado, agora unificado em torno de conceitos como colônia e colonial, afastava-se do presente, mas os velhos vícios persistiam, e as promessas de uma nova ordem encontravam obstáculos renovados em um quotidiano político pulverizado pelos interesses particulares dos vários sujeitos empíricos. Ao mesmo tempo, os deslocamentos cronológicos que alargavam o futuro, multiplicando as expectativas quanto ao destino do novo (e diferente) Império, reduziam a tolerância com a lentidão comparativa do presente. Era cada vez mais difícil acreditar que o futuro estava à disposição ou mesmo sendo construído no presente. Sobreviver ao crescente afastamento entre expectativa e experiência significava não apenas a destruição do passado, ou seu distanciamento, mas também a constituição de estratégias compensatórias. Em Bonifácio, o futuro em fuga podia ainda ser experimentado com o auxílio das imagens antigas que, num contexto de universalidade do humano, serviam de ponte entre o presente e o futuro, amortecendo as tensões típicas da modernidade.

\footnotetext{
${ }^{43}$ SILVA, José Bonifácio de Andrada e. Carta ao Sr, Menezes, 16 de março de 1827. In: The Question Concerning Technology and Others Essays. Nova York: Harper Torchbooks, 1977 , . Obra política, p. 167. Grifo meu. É difícil determinar se Bonifácio referia a Ferreira ou recebia a frase direto do filósofo alemão ou ainda de outra fonte. O fato é que a expressão era de uso comum no período.
} 
Essa afirmação cada vez mais sentimental das imagens antigas indicava que o quadro em 1827 estava visivelmente fraturado. Havia resistido a várias ondas de perspectivização, mas para muitos já não parecia suficiente. Para a nova geração, que sobreviveu ao processo de Independência e foi responsável pela organização do Estado, a compreensão do mundo luso-brasileiro como um mesmo sistema não parecia mais possível ou desejável. A ameaça de descontinuidade, não apenas com a história de Portugal, mas com a própria Europa, teria que ser respondida com novos e mais vigorosos artifícios.

Paralelamente à afirmação dessa compreensão sistêmica, a idéia de aclimatação preparava a compreensão da América como produtora de diferença. De Pradt, em 1818, já apontava essa possibilidade. Em vez de afirmar a identidade dos portugueses dos dois lados do Atlântico, como fazia Bonifácio, antevê uma América produtora de alteridade:

Le premier ministère brésilien qui entendra bien des ses affaires, ne s'y méprendra pas; lorsque la cour du Brésil aura suffisamment respiré l'air de l'Amérique, elle se trouvera toute americaine par le seule force de son séjour dans ce pays. Elle s'imprégnera, malgré elle, des proprietés inhérentes au sol américaine, et, semblable à ces plantes auxquelles la transplatation fait perdre une partie des fomes et de la saveur de la terra natale, et contracter celles de leur nouveau climat, la cour du Brésil, dans un espace de temps fort rapproché, cessera d'être européene, et de regarder l'Europe avec des yeux européens, pour ne plus considérer que de la manière dont l'envisagent les autres Américains. ${ }^{44}$

Para os homens nascidos no Brasil que diferentemente de Bonifácio não participaram da experiência comum de organização do império português, que não o experimentaram senão como colonos, a dimensão dessa história, o seu sentido de continuidade, era bem mais problemático. Da mesma forma, para as gerações seguintes, a experiência do império precisou se conformar com sua dimensão brasílica, perdendo-se paulatinamente o espaço privilegiado de mediação e continuidade, a administração de uma máquina burocrática comum.

No projeto restaurador, a aceleração do tempo histórico, entendida como os progressos das ciências, que para Bonifácio avançavam geometricamente,

\footnotetext{
${ }^{44}$ PRADT, M. de. Les six derniers mois de l'Amérique et du Brésil, p. 14.
} 
ajudava a constituir a continuidade. Para Portugal, significava a possibilidade de restauração com a ajuda da ciência. O futuro já começara e não estava tão distante, pois suas expectativas ainda podiam ser claramente mediadas e comparadas com os modelos da Antigüidade. Com a experiência da Revolução Francesa, seu desenvolvimento napoleônico e a transferência da Corte para o Rio de Janeiro essa aceleração do tempo começa a sair de controle; o futuro acelera, mas distanciando-se e deslocando-se das experiências do presente. A imagem desse futuro é cada vez menos o reflexo do mundo antigo e começa a guardar algo de imponderável. Novas operações cronológicas foram necessárias para situar esse futuro em fuga em uma cronologia longa e contínua, em que a idéia de desenvolvimento progressivo começou a movimentar o quadro. A um futuro que se afasta corresponde um passado em profundidade. Entre essas duas dimensões o presente se contrai, perde sua força epistemológica, lentamente torna-se apenas um momento em uma cronologia aparentemente infinita entre passado e futuro.

Nessa compreensão sistêmica do tempo e da história, o novo não caracteriza uma ruptura, uma singularidade irredutível, mas a realização extrema de um tipo. Tanto um passado quanto um futuro afastados exigem técnicas de perspectivização. O observador está envolvido não de fora, olhando de um ponto de vista universal a partir do qual todos os pontos são eqüidistantes, mas de dentro do quadro. O relato da constituição dessas técnicas de perspectivização diacrônica é um desafio que foi enfrentado nas décadas seguintes. O esforço de descrição do universo precisaria ser estabelecido em novas bases e o presente precisaria re-situar a sua identidade para além de si mesmo, incorporando as várias camadas de alteridade que os sistemas pareciam produzir, contrariando todas as expectativas de harmonização.

\section{0 Brasil nação}

Uma das características mais destacadas da produção intelectual do período de consolidação do Estado Imperial tem sido a continuidade com alguns temas centrais que mobilizaram o mundo luso-brasileiro nas primeiras décadas do século XIX. Sem negar a evidência empírica dessa afirmação, é preciso, entretanto, avançar no entendimento do que há de próprio nas transformações conceituais acentuadas a partir da década de $1830 .^{45}$

\footnotetext{
${ }^{45}$ A permanência de temas clássicos não foi privilégio do século XIX brasileiro. A preponderância cultural francesa, ao longo do XIX, reservou um espaço significativo para a cultura clássica. No
} 
Mesmo que conceitos como "civilização", "literatura", "nação" e "história" continuem a habitar os textos e as preocupações desses homens, eles sofrem uma progressiva historicização que marca uma descontinuidade fundamental com o período anterior. Embora seja possível, ao longo do século XIX, constatar o uso, em um mesmo autor ou texto, das versões não-substantivas e substantivas desses e de outros conceitos, é a historicização da realidade que organiza os discursos.

Afirmar essa descontinuidade não significa dizer que esses homens não procuraram se constituir como continuadores do projeto iniciado com a Independência. Muito pelo contrário, essa vontade de continuidade é um dos marcos fundamentais do processo de historicização.

A preocupação com a história e a necessidade de seu registro não seria uma prerrogativa das novas gerações. No seu "Congrès de Panamá", De Pradt estabelecia a tarefa para o período pós-revolucionário na América. Feita a independência, tratava-se apenas de escrever a história:

La victoire est restée à l'Amérique; à son égard, notre foi égalait notre amour, nous n'avons pas du l'abandonner dans l'acte de clôture de sa révolution, car désormais elle entre dans la carrière ordinaire de tous les gouvernemens, et dorénavant, chez elle, tout sera règle comme plus à traiter de la révolution de l'Amérique, mais seulement à écrire son histoire, comme on le fait le reste du monde. ${ }^{46}$

Não era diferente a expectativa de Bonifácio. Em sua concepção de história, era necessário proceder ao levantamento de todos os fatos físicos e morais pertencentes ao novo país. É bom lembrar que parte dos homens de ciência acreditava, como Cuvier, que haveria um único conjunto de formas imutáveis, que todo organismo era simplesmente a atualização de uma forma conhecida ou ainda não descrita. Por isso, em Bonifácio, quando se fala em história, o trabalho imaginado é fundamentalmente descritivo. Uma vez identificados os "sucessos" e suas relações causais, o trabalho científico estaria encerrado e pronto para ser aplicado. A diversidade dos fenômenos morais e físicos era imensa, embora limitada, e poderia ser organizada com base nas leis gerais da natureza.

Brasil, entretanto, essa permanência foi reforçada pelo sistema de ensino e valores culturais. Cf. CANDIDO, Antônio. Formação da literatura brasileira, vol. I, p. 288 e SOUZA, Roberto Acízelo de. O império da eloqüência, p. 116.

${ }^{46}$ PRADT, M. de. Congrès de Panama, p. vi. 
Mesmo que a idéia da descrição geral permaneça como meta, os mecanismos conceituais para realizar sua totalização transformam-se rapidamente nas décadas seguintes. A permanência da retórica da nação esconde o fato de já não se falar mais da mesma coisa. Se a nação, para os homens da geração de Bonifácio, era uma realidade objetiva e simples - de modo geral, o conjunto de cidadãos organizados em um sistema político -, para a geração que se forma ao longo do processo de Independência e assume a liderança intelectual a partir da década de 1830, ela reveste-se de uma espessura histórico-cultural. ${ }^{47}$

Nenhum outro conceito exemplifica melhor essas transformações do que o de civilização. Da forma como era geralmente utilizado, significava pouco mais que a soma das realizações intelectuais de uma comunidade. Seus indicadores eram muito objetivos, fundados nos progressos materiais e institucionais da Europa. É no horizonte desse critério "quantitativo" de civilização que se poderia entender ainda uma frase polêmica como a atribuída a Bernardo Pereira de Vasconcelos, que, em seu discurso no Senado em 1843, dizia: "a África tem civilizado a América!". ${ }^{48}$ Obviamente, a África civiliza não porque traria alguma contribuição cultural para uma possível "civilização" brasileira, mas porque forneceria os recursos materiais necessários para que o Brasil adquirisse os mesmos progressos que a Europa civilizada desfrutava.

Com a historicização do conceito de civilização, o Brasil é chamado a contribuir com aquilo que teria de singular como nação. ${ }^{49}$ Para isso, foram instrumentais as transformações no conceito de história universal, que deixa de ser apenas a soma mecânica de histórias particulares para adquirir um campo de experiência próprio, para o qual deveria contribuir cada uma das nações modernas. A versão eclética de Victor Cousin desta História Universal teria uma rica fortuna entre os intelectuais atuantes na Corte. Em 1828, na sua "Introduction à l'histoire de la philosophie", Cousin escreve que os objetos centrais de uma

\footnotetext{
${ }^{47}$ Sobre as diferentes versões do conceito de nação na Europa entre 1780 e 1848, ver HOBSBAWM, Eric. A nação como novidade: da revolução ao liberalismo. In: Nações e nacionalismos desde 1780, p. 27-61.

${ }^{48}$ Cf. VASCONCELOS, Bernardo Pereira de. Discurso no Senado em 25 de abril de 1843. In: CARVALHO José Murilo de. Bernardo Pereira de Vasconcelos, p. 268. Para uma interpretação do significado social e político da frase, ver MATTOS, Ilmar Rohloff de. O Tempo Saquarema: A Formação do Estado Imperial. São Paulo: Hucitec, 1990. p. 126.

${ }^{49}$ O substantivo "civilização" aparecerá, pela primeira vez, na edição de 1831 do dicionário de Moraes: "s. f. O ato de civilizar: o estado de povo civilizado". O primeiro sentido, indicando mais a ação do que o estado, é o que predomina nos textos de Bonifácio.
} 
história da humanidade seriam “[...] les idées diverses représentées par lês divers peuples qu'il faudrait atteindre et dégager". ${ }^{50}$

$\mathrm{Na}$ frase de Cousin está em jogo uma série de novos instrumentos intelectuais forjados paralelamente ao surgimento do conceito moderno de história. Acreditar que uma nação, em seu desenvolvimento histórico concreto, "expressa" uma idéia requeria todo um aparato epistemológico novo, por exemplo, algo que permitisse totalizar um conjunto semântico - a nação - cuja figura completa estendia-se tanto para o passado quanto para o futuro. A superação do modelo do sistema significava a incorporação de outras camadas do tempo, mesmo distantes, como parte constitutiva do presente. Essa compreensão, uma das marcas da autoconsciência da modernidade, não é alcançada como uma progressão lógica. Ao contrário, cada grupo social constitui seu caminho próprio no enfrentamento desses problemas.

Um conjunto de eventos históricos, em especial a Independência, colaborou para a fragmentação do campo discursivo herdado do século XVIII e possibilitou a consolidação de uma série de novos conceitos orientados pelo movimento geral de historicização da realidade. Os caminhos trilhados pelo Brasil após a Independência pareciam desqualificar a via "regeneradora" proposta por Bonifácio. $\mathrm{O}$ tempo não podia mais ser experimentado como uma dimensão universal, produtora de um repertório limitado de tipos. À medida que a nova nação não repetia apenas o velho Portugal - cada vez mais excluído do progresso moderno, e mesmo identificado com o atraso -, o tempo passava a ser experimentado como produtor de diferenças e singularidade. Esse deslocamento da experiência do tempo, de universal para produtor de diferenças, exigia a historicização de camadas cada vez mais amplas da realidade. Se a nação não é mais apenas um conjunto de homens racionais, mas uma individualidade, a forma de conhecê-la não poderia se limitar a um catálogo exaustivo, mas sim incluir a compreensão de sua história. A sociedade, a natureza, o território e o universo passam a figurar como sujeitos portadores de um tipo de singularidade que se revela com o passar do tempo. Os brasileiros não poderiam se contentar

\footnotetext{
${ }^{50}$ COUSIN, Victor. De la philosophie de l'histoire. In : GAUCHET, Marcel. (org.) Philosophie des sciences historiques, p. 161. No contexto francês o tema clássico da História Universal adquire um novo significado, muitas vezes resumido na idéia de uma História da Humanidade. O contexto alemão é bem estudado por Koselleck, que mostra a passagem da Historia Universalis para a Weltsgeschichte. Cf. KOSELLECK, Reinhart. Le concept d'histoire. In : l'histoire, p. 62. . L'expérience de
} 
em ser apenas os portugueses do Brasil; por isso, a busca de novas formas de construção da identidade coletiva.

Os eventos do passado, como partes de uma totalidade em movimento, deveriam ser interpretados e compreendidos para se tornarem disponíveis como realidade substantiva e mediada. A literatura, que já na geração de Bonifácio aparecia como realização máxima do progresso e da civilização, mantém seu estatuto privilegiado - em particular sua posição de índice de civilização -, mas passa a ser vista de modo radicalmente novo. O entendimento das letras como conseqüência e produto da ação do homem racional, ou seja, do cidadão, é abandonado em favor de uma compreensão da literatura como produção do gênio e expressão singular de uma nacionalidade. Como parte mais visível e permanente da história de uma nação, a literatura assume o papel de "cápsula do tempo" da nacionalidade, lugar no qual, através de procedimentos da história da literatura, uma imagem da identidade nacional poderia ser obtida.

Conceitos como nação, civilização e literatura são as pontas mais visíveis dessa descontinuidade na experiência do tempo. Por isso, a centralidade do conceito de história, pois ele devia lidar não apenas com questões próprias ao conhecimento do passado, mas também oferecer novas formas de compreensão da própria realidade.

As demandas para constituição da história considerada como campo disciplinar autônomo eram alimentadas pelo papel totalizador da experiência social conferido aos fenômenos históricos. O destino da nação, sua identidade e legitimidade, a vida política, o lugar individual, todas essas questões pareciam exigir respostas históricas. Por isso a desqualificação política e cultural progressiva do discurso liberal ilustrado fundado em conceitos universais como razão e liberdade. O cidadão racional é transformado no povo brasileiro a ser inventado, o otimismo perante a ação individual é substituído pela crença na autoridade do Estado e seu corpo de especialistas, o presente deixa de ser o ponto de vista privilegiado para se tornar apenas uma parte pequena de um processo histórico que precisa ser interpretado por complexas operações hermenêuticas, lugar dos interesses e das paixões, incapaz de produzir um juízo universal sobre seus próprios problemas. Julgar o presente e escrever sua história serão tarefas delegadas ao futuro. O território deixa de ser apenas um espaço homogêneo a conquistar e torna-se um símbolo nacional, lugar singular e exótico. O selvagem, que para homens como Bonifácio seria matéria-prima da cidadania, é agora simbolicamente incorporado ao imaginário nacional e positivamente extermi- 
nado. A escravidão torna-se rotineira como marca singular de uma civilização também singular, cuja solução pertence agora a um tempo histórico lento, sem pressa, portador de razões ocultas para os homens do presente.

O aprofundamento do passado, como conseqüência, entre outros fatores, da ênfase na singularidade do presente, exigia um novo entendimento dos eventos. Agora eles passavam a representar fragmentos de uma totalidade em movimento. A apreensão dessa totalidade pelo presente não obedecia mais ao otimismo demonstrado por Bonifácio, já que a entendia como sistema. Vislumbrar essa totalidade em movimento significa decifrar, através dos fragmentos históricos, o sentido da história nacional. Essa tarefa foi enfrentada nos primeiros anos do IHGB por homens como Januário da Cunha Barbosa, Raimundo José da Cunha Matos, Gonçalves de Magalhães e o Visconde de São Leopoldo. Entretanto, o trabalho era dificultado pela consciência nascente de que os interesses e parcialidades dos homens vivos poderiam distorcer a compreensão dos eventos e, logo, do destino histórico da comunidade. Para enfrentar esse problema, a positividade dos fatos é transformada em único critério de verdade.

Portanto, a preocupação com o levantamento exaustivo dos fatos assume significados completamente distintos nos dois momentos históricos. No primeiro, ele é, por si só, um procedimento suficiente; no segundo, é apenas regulador. Nos anos iniciais do IHGB é possível notar a tensão entre as demandas por um levantamento exaustivo dos fatos, herdeira de uma concepção de história ligada à crônica e à cronologia, e uma compreensão hermenêutica e narrativa que, mesmo dependente do estabelecimento positivo dos fatos, exigia uma abordagem seletiva e hierárquica dos eventos.

A aceleração do tempo e a consciência da singularidade dos eventos têm como conseqüência direta uma aguda percepção da finitude, seja individual, geracional ou coletiva. A obsessão pelas ruínas e pelos monumentos do passado são efeitos dessa consciência da finitude. Por isso, ao lado das demandas por sentido e direção, de maneira complementar, a preocupação com a história também assumia a função de registro monumental do presente, ou seja, de memória. O projeto da História Geral do Brasil, tal como debatido no IHGB, culminava essas duas demandas, ou seja, sentido e monumentalização.

\section{Fontes e bibliografia citada}

ARAÚJO, Valdei Lopes de. A experiência do tempo: modernidade e historicização no Império do Brasil (1813-1845). Rio de Janeiro: Tese de Doutorado, PUC-Rio, 2003. 
ARAÚJO, Valdei Lopes de. José Bonifácio, Shakespeare e os Gregos: a língua do Brasil e a imagem nacional. Almanack Braziliense, São Paulo, USP, n. 4, nov. 2006, pp. pp. 83-93.

ARAÚJO, Valdei Lopes de. Para além da autoconsciência moderna: a historiografia de Hans-Ulrich Gumbrecht, Varia História, Belo Horizonte, vol. 22, n. 36, jul./ dez. 2006, p. 314-328.

BERBEL, Marcia Regina. A nação como artefato: deputados do Brasil nas cortes portuguesas (1821-1822). São Paulo: Hucitec/Fapesp, 1999.

CANDIDO, Antonio. Formação da Literatura Brasileira: Momentos decisivos. Belo Horizonte/Rio de Janeiro: Itatiaia, 1997.

CARVALHO, José Murilo de (org.). Bernardo Pereira de Vasconcelos. Coleção Formadores do Brasil. São Paulo: Editora 34, 1999.

COUSIN, Victor. De la philosophie de l'histoire. In : GAUCHET, Marcel(org.). Philosophie des sciences historiques. Lille: Presses Universitaires de Lille, 1988.

DE PRADT. Congrès de Panama. Paris: Béchet Aine/Libraire-Éditeur, 1825.

DE PRADT.. Les six derniers mois de l'Amérique et du Brésil. Paris: F. Béchet Libraire, 1818.

FERREIRA, Silvestre Pinheiro. Preleções Filosóficas. Introdução de Antônio Paim. São Paulo: Edusp, 1970.

GUMBRECHT, Hans Ulrich. Cascatas de modernização. In: . Modernização dos sentidos. São Paulo: Editora 34, 1998, p. 9-32.

HABERMAS, Jürgen. $O$ discurso filosófico da modernidade. Lisboa: Dom Quixote, 1990.

HEIDEGGER, Martin. The age of the world picture. In: . The Question Concerning Technology and Others Essays. Nova York: Harper Torchbooks, 1977, p. 115-54.

HOBSBAWM, Eric. Nações e Nacionalismos desde 1780: programa, mito e realidade. Rio de Janeiro: Paz e Terra, 1990.

KOSELLECK, Reinhart. L'expérience de l'histoire. Paris: Gallimard, 1997.

KOSELLECK, Reinhart. História dos conceitos e história social. In: . Futuro Passado: contribuição à semântica dos tempos históricos. Rio de Janeiro: Contraponto/PUC-Rio, 2006, p. 97-118.

KOSELLECK, Reinhart. Modernidade - sobre a semântica dos conceitos de movimento na modernidade. In: .Futuro passado: contribuição à semântica dos tempos históricos. Rio de Janeiro: Contraponto/PUC-Rio, 2006, p. 267-303.

LYRA, Maria de Lourdes Viana A Utopia do Poderoso Império. Portugal e Brasil: Bastidores da República 1798-1822. Rio de Janeiro: Sete Letras, 1994.

MATTOS, Ilmar Rohloff de. O Tempo Saquarema: A Formação do Estado Imperial. 
São Paulo: Hucitec, 1990.

NEVES, Lucia Maria Bastos Pereira das. Corcundas, constitucionais e pés-dechumbo: a cultura política da Independência, 1820-1822. Rio de Janeiro: Revan/Faperj, 2003.

PHILLIPS, Mark Salber. Society and Sentiment. Genres of historical writing in Britain, 1740-1820. Princeton: Princeton University Press, 2002.

PIMENTA, João Paulo. Portugueses, americanos, brasileiros: identidades políticas na crise do Antigo Regime luso-americano. Almanack Braziliense, São Paulo, USP, $\mathrm{n}^{\circ}$ 3, maio de 2006, p. 69-80.

SILVA, Ana Rosa Cloclet da. Inventando a Nação: intelectuais ilustrados e estadistas luso-brasileiros na crise do Antigo Regime Português. São Paulo: Hucitec, 2006.

SILVA, Antônio de Moraes. Dicionário de Língua Portuguesa. Quarta edição, reformada, emendada, e muito acrescentada pelo mesmo autor. Posta em ordem correta, e enriquecida de grande número de artigos e dos sinônimos por Theotônio José de Oliveira Velho. Lisboa: Impressão Régia, 1831.

SILVA, José Bonifácio de Andrada e. Discurso, contendo a história da Academia Real das Ciências, desde 25 de junho de 1814 até 24 de junho de 1815. In:

Obras Científicas, Políticas e Sociais. Coligidas e reproduzidas por Edgard de Cerqueira Falcão. São Paulo: Grupo de Trabalho Executivo das Homenagens ao Patriarca, 1965, v.1.

SILVA, José Bonifácio de Andrada e.. História da Academia Real das Ciências de Lisboa. Lido em 1818. In: . Obras Cientificas, Políticas e Sociais. Coligidas e reproduzidas por Edgard de Cerqueira Falcão. São Paulo: Grupo de Trabalho Executivo das Homenagens ao Patriarca, 1965, v.1.

SILVA, José Bonifácio de Andrada e.. Discurso histórico recitado na sessão pública de 24 de junho de 1819 pelo secretário JBAS. In: __ . Obras Cientificas, Políticas e Sociais. Coligidas e reproduzidas por Edgard de Cerqueira Falcão. São Paulo: Grupo de Trabalho Executivo das Homenagens ao Patriarca, 1965, v.1.

SILVA, José Bonifácio de Andrada e.. Necessidade de uma academia de agricultura no Brasil. In: . Obra política. Organização de Octaciano Nogueira. Brasília: Senado federal, 1973, v.2.

SILVA, José Bonifácio de Andrada e.. Lembranças e Apontamentos do Governo Provisório da Província de São Paulo para os seus deputados, mandado publicar por ordem de sua Alteza Real, Príncipe Regente do Brasil, a instâncias dos mesmos senhores deputados. In: . Obra política. Organização de Octaciano Nogueira. Brasília: Senado federal, 1973, v.2.

SILVA, José Bonifácio de Andrada e.. Representação de 31 de dezembro de 1821. In:__. Obras Cientificas, Políticas e Sociais. Coligidas e reproduzidas por Edgard de Cerqueira Falcão. São Paulo: Grupo de Trabalho Executivo das 
Homenagens ao Patriarca, 1965, v.2.

SILVA, José Bonifácio de Andrada e.. Suplemento ao número 4 da Gazeta do Rio, de 8 de janeiro de 1822. In: . Obras Cientificas, Políticas e Sociais. Coligidas e reproduzidas por Edgard de Cerqueira Falcão. São Paulo: Grupo de Trabalho Executivo das Homenagens ao Patriarca, 1965, v2.

SILVA, José Bonifácio de Andrada e.. Discurso lido em 26 de janeiro de 1822. In: . Obras Cientificas, Políticas e Sociais. Coligidas e reproduzidas por Edgard de Cerqueira Falcão. São Paulo: Grupo de Trabalho Executivo das Homenagens ao Patriarca, 1965, v.2.

SILVA, José Bonifácio de Andrada e.. Manifesto do Príncipe Regente do Brasil aos Governos e Nações Amigas, datado de 6 de agosto de 1822. In:

Obras Cientificas, Politicas e Sociais. Coligidas e reproduzidas por Edgard de Cerqueira Falcão. São Paulo: Grupo de Trabalho Executivo das Homenagens ao Patriarca, 1965, v2.

SILVA, José Bonifácio de Andrada e.. Carta de... ao Sr. Menezes, datada de 14 de novembro de1825. In: . Obra política. Organização de Octaciano Nogueira. Brasília: Senado federal, 1973, v.2.

SOUZA, Roberto Acízelo de. O Império da Eloqüência: retórica e poética no Brasil oitocentista. Rio de Janeiro: Eduerj, Uduff, 1999. 